RED CROSS HOSPITAL SERVICES.

\section{THE NEW DIRECTOR.}

The Joint Council of the Order of St. John of Jerusalem and the British Red Cross Society has appointed Dr. F. N. Kay Menzies, F.R.C.P., to be Director of the Joint Council's Department of Hospital and Medical Services in succession to the late Sir Napier Burnett, K.B.E.

The appointment is one which will, undoubtedly, be welcomed by all concerned in the hospitals with which the Joint Council's activities are associated. Dr. Menzies has had a long and distinguished career in medicine, and possesses in high measure qualities and knowledge which fit him to deal with the varied

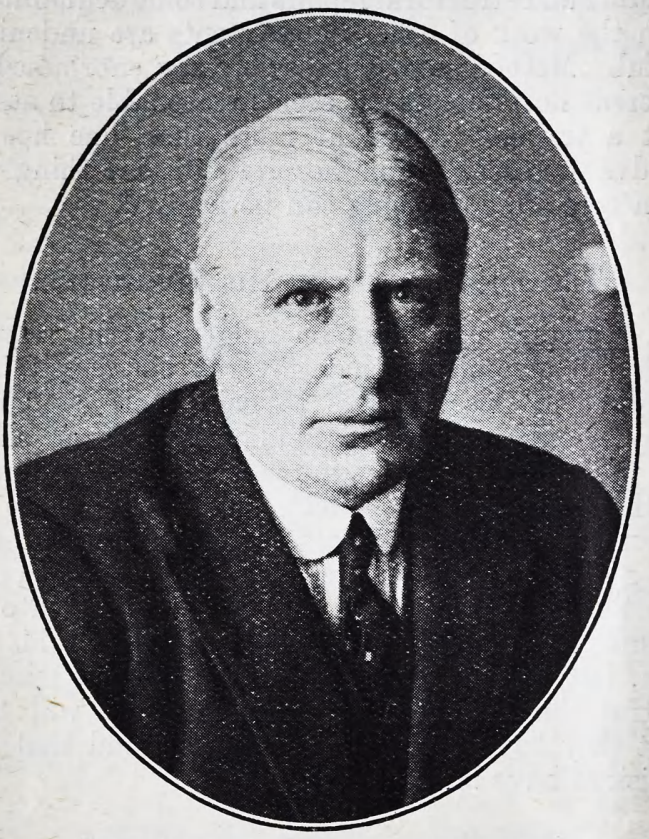

[Fl. p press.

Dr. F. N. Kay Menzies

problems of hospital service. His experience in this direction has embraced, among other things, the work of House Physician to the Royal Infirmary, Edinburgh, and the Children's Hospital, Great Ormond Street, of Senior House Physician at the Hospital for Consumption, Brompton, and Assistant Lecturer in the Public Health Laboratories at University College, London.

As Principal Assistant Medical Officer in the Public Health Department of the London County Council, Dr. Menzies has been closely concerned with Public. Health problems in their wider aspect, and he is in particular an authority on such subjects as tuberculosis, maternity, child welfare, etc. He is chairman of the Executive Committee of the Central Council for Infant and Child Welfare at Carnegie House, and a member of the Executive Committee of the Central Council for Rescue and Preventive Work For many years Dr. Menzies has been a member of the Council of the National Association for the Prevention of Tuberculosis, and was one of the founders of the Burrow Hill Colony for Tuberculous ex-Service Men at Frimley. $\mathrm{He}$ represented the British Red Cross Society at the Inter-Allied Conferences at Cannes (1919), Geneva (1920), and Copenhagen (1921), has been secretary of the Hygiene Section of the International Congress on Applied Chemistry (London), and is a Fellow of the Royal Society of Medicine and of the Royal Society of Arts.

His academic career took him to the Universities of Edinburgh, London, Vienna, and Berlin, and he has been a University examiner both in London and liverpool. In a word, his equipment is such as to fit him admirably to fill a position in which breadth of view, familiarity with detail, insight and understanding must all be combined in a very special degree.

\section{THE CARE OF THE BABY.}

Viscount Astor had a satisfactory year's progress to report at the Annual Meeting of National Baby Week Council, which took place at Carnegie House on March 12. There was, however, he said, a danger that they might-become apathetic and satisfied with what had been accomplished. The reduction of the infantile mortality to 69 was most encouraging, but there was much to do still in that direction. The average for Cambridge, for instance, was only 38 , but at Oldham it was 112. Again, 80 to 90 per cent. of children were born healthy, but at the age of five 35 to 40 per cent. had acquired some physical defect. That had got to be remedied and the root causes attacked. It was their job to make the nation say what the Queen herself had said in a recent message to the Council, "that her interest in the movement was unabated."

\section{Conference on Birth Control.}

After the reading of the Annual Report by Dr. Eric Pritchard, Chairman of the Executive Committee, and the election of officers, a conference was held on "The Size of the Family and its Economic Circumstances in relation to the Welfare of Children under Five." This practically resolved itself into a debate on Birth Control, in which the more conservative standpoint was taken by Principal Garvie and Lady Nott-Bower. Dr. Elizabeth Sloan-Chessar urged that instruction on the use of contraceptives might be given to mothers when necessary at infant welfare centres and that the Ministry of Health should remove its taboo on the subject. Breezy speeches were contributed by Mr. E. B. Turner, F.R.C.S., and the Medical Officer of Health forDeptford.

\section{An X-Ray Victim.}

Efforts are being made to recognise more adequately the work done by Mr. Ernest Harnack, a former X-Ray operator of the London Hospital, who, like his successor Mr. Blackwell, lost both his hands. Mr. Harnack receives a pension of $£ 250$ from the hospital and it is thought possible that the Carnegie Hero Fund might consider his case. For a long time after Mr. Harnack was severely affected he stuck to his work. His sufferings were terrible. In co-operation with Messrs. Dean Mr. Harnack invented the lead glass screen which protects present-day operators, but this discovery was too late to save himself. 